prevent it reaching the bookshelves of many entomologists. It deserves a much wider audience, for New's thoughtful work not only points the way ahead for Australians, but provides a very valuable summary for conservationists in the northern hemisphere too.

$N$. Mark Collins, IUCN Conservation Monitoring Centre

\section{The Amazing Armadillo}

\section{L.L. Smith and R.W. Doughty}

University of Texas Press, Austin, Texas, 1984, HB $\$ 13.95$, PB $\$ 6.95$

I first came across the armadillo in the delightfu Kipling story of childhood. Since then, I have learned all too little about the creature. Hardly anybody writes about its natural history, its ecology or behaviour, its conservation status, whatever. There have been a few notes about its use as a research model for leprosy, and that is about all. All the more welcome, then, is this account of the nine-banded armadillo in the southern US. After reaching northwards from Mexico about 150 years ago, the armadillo has actually extended its range hundreds of miles across southern and south-eastern US-a rare ecological success story.

The book not only deals with the basic biology of the animal and its spreading distribution, it also examines recent popular interest in the armadillo as a symbol of popular culture. The creature certainly seems to have ingratiated itself into the folklore of Texas and several other states-and this additional dimension is splendidy treated by the two authors, being geographers at the University of Texas. Equally to the point, the authors write not only with scientific substance, but also with an engaging style. Altogether, this is a worthy publication, even if rather expensive in hardback form.

Dr Norman Myers, Consultant in Environment and Development

\section{The Wild Sheep of the World}

Paul Valdez

Wild Sheep and Goat International, Mesilla, New Mexico, $\$ 40$

As was the case with most ungulates, the early literature on wild sheep saw them primarily as hunting trophies, with all the emphasis on bigger and better 'heads'. In recent years, there has been a resurgence of interest, especially from the point of view of social organization and behaviour, with the pioneering field work of Geist in North America and Schaller in the Himalayas, demonstrating, amongst other things, the functional significance of bigger and better heads. A further recent development has been the elucidation of the otherwise intractable problem of delimiting the species, using evidence from chromosomes. The time would therefore seem ripe for a worldwide review of the group to bring together all this diverse and scattered information.

Disappointingly, this volume only goes a small way towards fulfilling this. The classification is indeed brought up to date, although somewhat marred by the frequent use of the cumbersome and quite unnecessary terms 'moufloniforms', 'argaliforms' and 'pachyceriforms' for the three groups (particularly redundant in view of the fact that the first two are, in the classification used, synonymous with the single species Ovis orientalis and $O$. ammon).

Brief introductory chapters on the discovery of wild sheep, their life-history and habitats are followed by two- or three-page accounts of each subspecies, with descriptions mostly quoted verbatim from early sources. A final chapter, by J.H. Batten, extols the delights of sheep hunting in terms that will seem strangely archaic to most readers. Both hunters and conservationists will be disappointed that the range of each form is only given briefly as the maximum historical range, with no information on current status nor on the problems of conservation and management.

This then is a handbook that will appeal mainly to the hopefully dwindling band of sheep hunters rather than to the increasing ranks of wildlife watchers.

G.B. Corbet, British Museum (Natural History)

\section{A Dictionary of Animal Names in Five Languages-Mammals \\ V.E. Sokolov}

Moscow: 'Russkiy yazyk', 1984, 3·30 rubles.

Obtainable from Collet's, Dennington Estate, Wellingborough, Northants NN8 2QT, UK, $\mathbf{~ 5 . 7 5 ~}$

Other multilingual dictionaries of animal names

Oryx Vol 20 No 1, January 1986 
(Klemm 1973, Gozmány 1979) cover the Palaearctic region and Europe, respectively. The volume under review presents 5391 names of mammals from the whole world fauna. Future volumes in the series (to be completed as a sixvolume set) will cover, in order, amphibians and reptiles, birds, fishes, insects, and invertebrates.

Sokolov's dictionary gives us Latin (scientific), Russian, English, German, and French names, with an impressive number of synonyms for the last four, an appendix of nearly 150 pages made up of alphabetical indexes for each of the five languages, and also an extra index of specific names in Latin. The main sources are Sokolov's own Systematics of Mammals (1973-9), Corbet and Hill's A World List of Mammalian Species (1980), and Honacki et al.'s (1982) Mammal Species of the World. The book is clearly printed on quality paper and with good use of bold type. Indication of gender for Russian, German and French nouns is another point in its favour.

Very modestly priced and nicely produced, this dictionary will surely be acquired by biological libraries as a matter of course. Many others, not least translators, will welcome its appearance and hope that the remaining volumes will follow very soon.

M.G. Wilson

\section{Livre Rouge des Vertébrés Menacés de la Corse (Corsican Red Book of Threatened Vertebrates)}

J.C. Thibault, M. Delaugerre and J.-F. Noblet

Parc Naturel Régional de la Corse, BP 417-F-20184-Ajaccio, Corsica, $1985,50 \mathrm{FF}$

Red Data Books (RDBs) are beginning to proliferate, and this is definitely a good thing. Local Red Data Books are an important weapon in the conservationist's arsenal to save endangered species. Many of the species included in volumes such as this excellent one on Corsica will never find a place in the international RDBs, yet locally their populations are important. Furthermore, as the revision time for the regional and international RDBs appears to be extending further and further into the future, shorter, more easily updated local RDBs will have an increasingly important role.

$\mathrm{RDBs}$ for areas of high conservation interest, such as Corsica, are of particular value. The herpetofauna, for instance, shows a considerable degree of endemicity. As in most other parts of Europe, it is the bats that are among the most threatened species. Twenty-four of the Island's 43 mammal species are bats, and 20 of these are listed in the Red Book.

The book is well laid out, with a large bibliography and excellent tables summarizing its contents.

John A. Burton

\section{Oxford Illustrated Encyclopedia: \\ The Natural World \\ Edited by Malcolm Coe \\ Oxford University Press, 1985, £15.95}

An attempt to cover the natural world in $\mathbf{3 7 5}$ pages of text and illustrations must necessarily be far from comprehensive, but it is easy to use and attractively presented.

\section{Endangered Plant Species of the World} and their Endangered Habitats: A Compilation of the Literature Meryl A. Miasek and Charles R. Long

The Council on Botanical and Horticultural Libraries Inc., 1985

Available for $\$ 5.00$ (US) and $\$ 6.00$ (outside US) including postage, from Mrs Elaine DiLorenzo, The Library, New York Botanical Garden, Bronx, New York 10458-5126, USA.

\section{Our Threatened Inheritance: Natural Treasures of the United States}

Ron Fisher, photographs by James P. Blair

National Geographic Society, Washington DC, 1984. No price given.

A lavishly illustrated survey of some of the national parks, forests, wildlife refuges and other federally owned areas in the US, the text examining the problems these areas face and exploring possible solutions.

\section{National Parks, Conservation, and Development: the Role of Protected Areas in Sustaining Society Edited by Jeffrey A. McNeely and Kenton R. Miller \\ Smithsonian Institution Press, Washington, 1985}

Available from Eurospan, 3 Henrietta Street, 